\title{
Evaluation of a Continuous Flow Paramagnetic Oxygen Analyser: The Junkalor Spirolyt ${ }^{\star}$
}

\author{
SERGE BAROLD $\dagger$, FELIX BURKART $\ddagger$, AND EDGAR SOWTON
}

From the Institute of Cardiology, London W.1

The use of paramagnetic analysers in determining the oxygen content of expired air is now common but the method employed usually involves collection of expired air in Douglas bags for later analysis with the paramagnetic meter. We report here our experience with a new paramagnetic analyser which is designed to present a continuous record of oxygen consumption and which may be used with a patient at rest or at any exercise level. The patient breathes via a mouth-piece from a supply of room air provided by a constant speed pump; the air stream is then led back to the Spirolyt, where the oxygen content is monitored and the carbon dioxide content is measured by a thermal conductivity method.

The air flow rate to and from the patient is adjusted with the aid of a flow meter, and differences in oxygen and carbon dioxide between room air and the expired air stream are recorded every four seconds on the Spirolyt chart. Absolute values for oxygen consumption and carbon dioxide production can then be obtained by multiplication of the percentage differences by the flow rate.

The paramagnetic measuring device is illustrated diagramatically in Fig. 1. The air is divided into two streams which are connected by a short tube at one end of which is a powerful magnet. The flow through this tube will be a function of the oxygen content of the air streams and this flow is used to cool a coil of platinum wire which forms part of a Wheatstone bridge circuit. The degree to which the bridge circuit goes out of balance is, thus, related to the oxygen content of the expired air stream. This application of the paramagnetic property of oxygen

Received January 27, 1966.

* Veb Junkalor Dessau, German Democratic Republic. Supplied by Shandon Scientific Co., 65 Pound Lane, London N.W.10.

† In receipt of a Smith \& Nephew Fellowship.

$\ddagger$ In receipt of a Fellowship from the Swiss National Fund has the advantage that no moving parts are necessary in the measuring equipment.

The flow rate can be adjusted to any level up to 120 litres per minute, and there are three scale ranges available for recording oxygen and carbon dioxide percentage differences. Scale 1 is for special applications and covers a range between 21 and 50 per cent difference, Scale 2 gives full scale deflection with a 6 per cent difference, and Scale 3 gives full scale deflection with a 2 per cent difference. The temperature of the air supplied to the patient is indicated by a thermometer in the stream, and the expired air is dried with calcium chloride before reaching the measuring head. The air passing through the $\mathrm{O}_{2}$ and $\mathrm{CO}_{2}$ measuring chambers is sampled at a constant rate of 30 litres/hour from the expired air stream, and this sampling rate can also

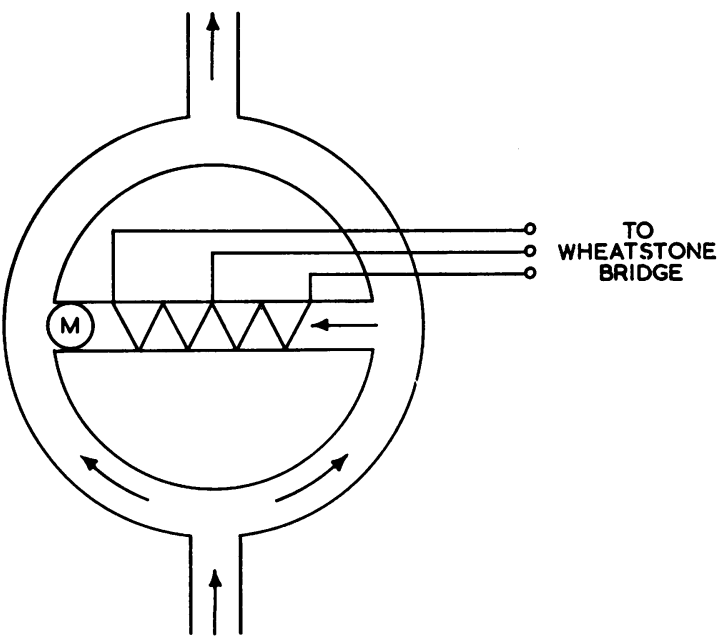

FIG. 1.-Diagrammatic representation of paramagnetic oxygen-measuring head. Gas flow in the cross tube is influenced by the magnet $(M)$ and cools a heated platinum wire forming part of a Wheatstone bridge circuit. 


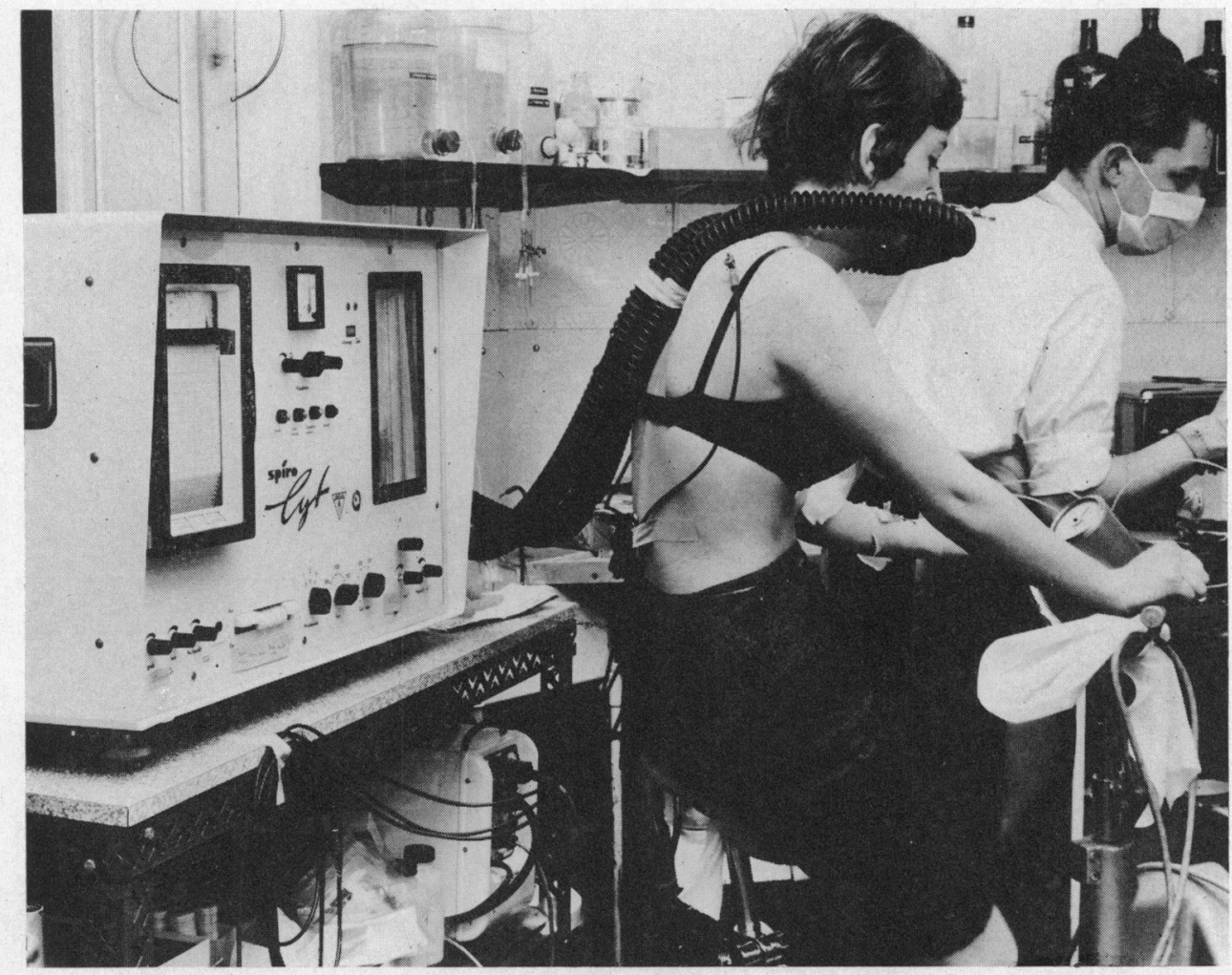

FIG. 2.-The Spirolyt in use.

be monitored on a flow meter. Electrical correction for barometric changes is provided, and the oxygen measuring head is contained in an aluminium case which is thermostatically maintained at a temperature of $40^{\circ} \mathrm{C}$. (Fig. 2).

Duplicate determinations of oxygen consumption and carbon dioxide production were obtained with the Spirolyt and by micro-Schölander analysis of expired air collected in Douglas bags which were connected to the exhaust side of the mouth-piece in place of the Spirolyt. This ensured that the subject continued to breathe room air supplied by the pump during analysis by the Spirolyt and during collection of exhaust air in the Douglas bag. There were 57 duplicate determinations made on 12 normal subjects: measurements were made at rest, and at various work loads up to $1200 \mathrm{kpm}$. $/ \mathrm{min}$. on a bicycle ergometer. Results were obtained on both the 2 per cent scale and the 6 per cent scale, and the air flow rate was adjusted so that maximum scale deflection was produced at the highest work load used.

\section{Results}

The results for oxygen analyses are shown in Fig. 3. For the 6 per cent scale 24 pairs were available and the regression line was $y=0 \cdot 88 x+17 \cdot 3$ $(R=0.980$ S.E. $=94.3 \mathrm{ml}$.). For the 2 per cent scale 33 pairs were available and the regression line was $y=1.08 x-117(R=0.986$ S.E. $=73.7 \mathrm{ml}$.).

The results for carbon dioxide analyses are shown in Fig. 4.

For the 6 per cent scale 24 pairs were available and the regression line was $y=0.79 x+88 . \quad(R=0.960$ S.E. $=142.3 \mathrm{ml}$.).

For the 2 per cent scale 33 pairs were available and the regression line was $y=0.96 x-11.2(R=0.994$ S.E. $=48 \cdot 2$ ).

When all the results irrespective of scale setting or air flow were considered together, 57 pairs were available. The regression line for oxygen was $y=0.96 x-42.3(R=0.984$ S.E. $=87)$ and the regression line for carbon dioxide was $y=0.86 x+36.9$ $(R=0.926$ S.E. $=187)$.

\section{Steady State Measurements}

When the Spirolyt was connected to a subject in a steady state, the time lag before the oxygen consumption trace showed a steady reading varied a little with exercise level and with air flow. The response time of the machine was of the order of 


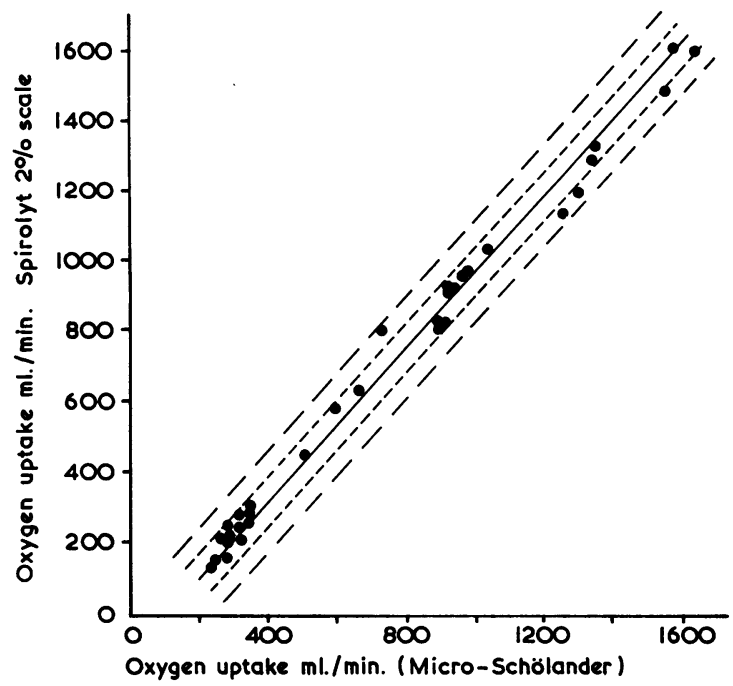

A

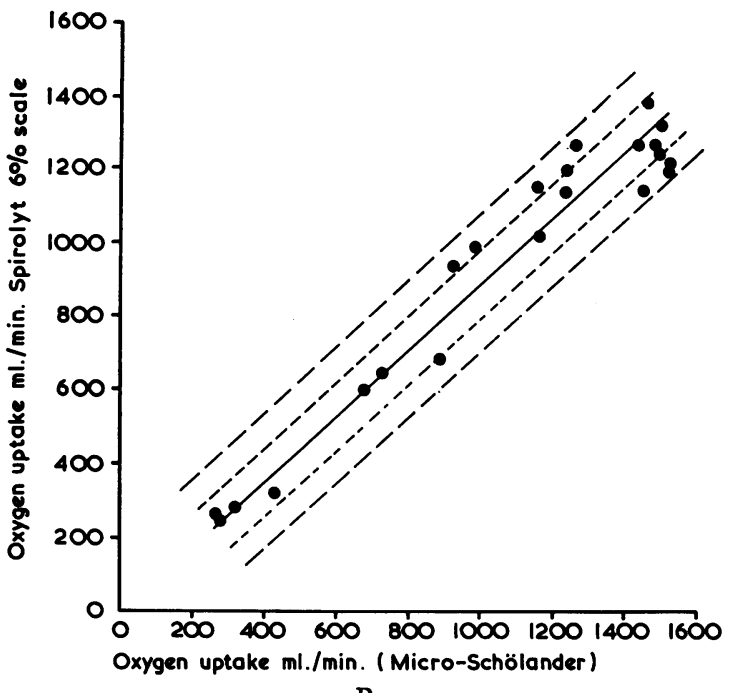

B

Fig. 3.-Comparison of values for $\mathrm{O}_{2}$ consumption measured with the Spirolyt and by micro-Schölander analysis of expired air. The regression line and \pm 1 S. E. and \pm 2 S. E. are indicated.

(A) Results using Spirolyt 2 per cent scale. 33 pairs.

(B) Results using Spirolyt 6 per cent scale. 24 pairs.

30 seconds with the subject at rest and 20 seconds when the subject was exercising at $900 \mathrm{kpm}$./minute.

The time taken for the subjects to reach a steady state with regard to oxygen consumption also varied with work load. The relation between the initial exercise level and the time before the subjects reached a steady state with regard to oxygen consumption is shown in Fig. 5. A steady state was

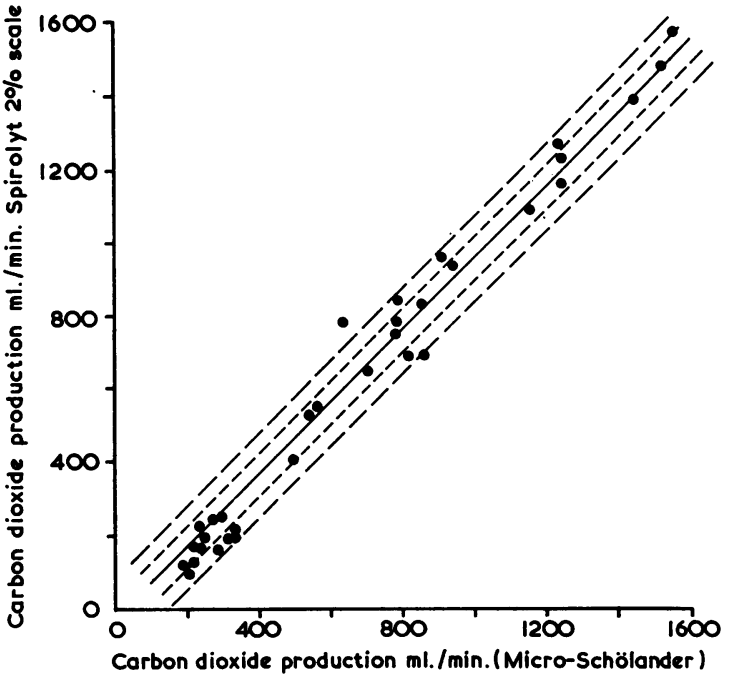

A

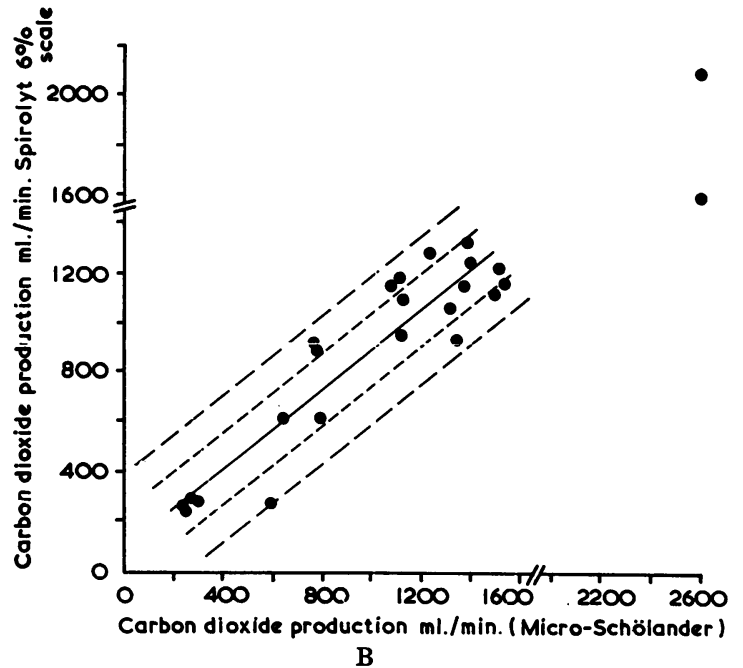

FIG. 4.-Comparison of values for $\mathrm{CO}_{2}$ production measured with the Spirolyt and by micro-Schölander analysis of expired air. The regression line and $\pm 1 \mathrm{~S}$. E. and $\pm 2 \mathrm{~S}$. E. are indicated.

(A) Results using Spirolyt 2 per cent scale. 33 pairs.

(B) Results using Spirolyt 6 per cent scale. 24 pairs.

reached in four minutes or less at all work loads though a shorter time sufficed for the lower work loads.

\section{Practical Considerations}

During the period of this investigation several difficulties were encountered with the apparatus, and we describe here briefly our experience over the period of one year. 


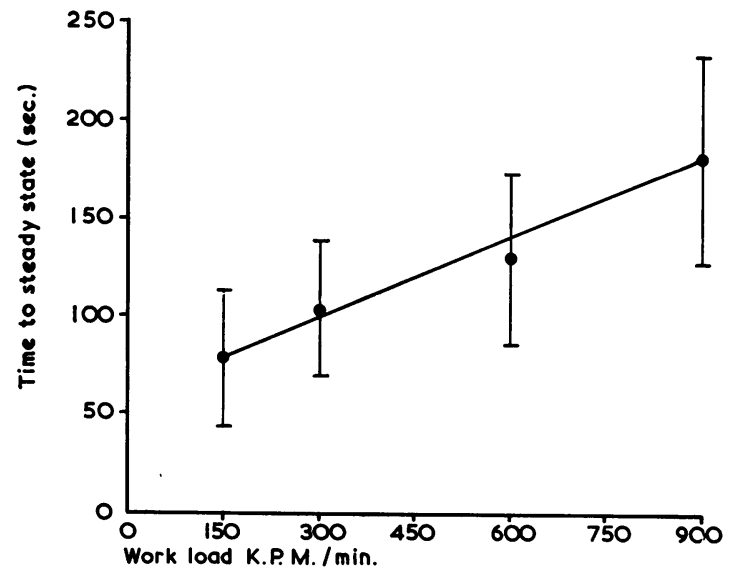

FIG. 5.-Mean times to reach a steady state with regard to oxygen consumption for the initial work load. Limits represent $\pm S$. D.

Base-line. The base-line is remarkably stable for a period of several hours provided the machine has warmed up completely and that no alterations are made to the flow or scale settings. At least two hours are necessary for the warming up process.

Control Settings. The fine control for the oxygen record is rather coarse in action and very small movements lead to large deflections on the chart. Base-line adjustment can be carried out most easily by switching off the chart driving motor during the time when the recorder is connected to the oxygen head; the final result cannot be checked until the chart drive is again started.

Air Flow Temperature. The electrically-driven pump supplying air to the machine results in an increasing air temperature to a maximum of about $28^{\circ} \mathrm{C}$., and we recommend that the pump be left running until this temperature is reached before an attempt is made to use the apparatus. It has proved impracticable to maintain the air stream temperature at $20^{\circ} \mathrm{C}$., though it is only at this temperature that the manufacturer's original calibrations were carried out. In our experience the error from this source has been negligible.

Noise. Probably the biggest disadvantage of this apparatus is the noise produced when it is in use. The rotary pump providing the air flow, the vacuum pump which samples air for analysis, and the escape valve through which the excess air is diverted, all produce a considerable amount of noise*.

Mouth-piece. The mouth-piece consists of a $2.5 \mathrm{~cm}$. diameter tube through which the air flow is pumped, with a side tube from which the subject breathes. Standard one-way valves on either side of the side tube prevent expired air being blown back towards the Spirolyt. Although the resistance to high air flows is considerable, we have not found this to be a problem, probably because the air is delivered by a pump and the patient does not have to increase his respiratory efforts to overcome mouth-piece resistance. A more serious problem is that an uncomfortable drying of the mouth and throat occurs at high exercise levels, and this factor sometimes limits the length of time the Spirolyt can be continuously used on one subject. This disadvantage is present with all methods of air collection involving a mouth-piece and during long investigations we recommend intermittent removal of the mouth-piece, the opportunity being taken to establish a new base-line during this time.

\section{Discussion}

The advantages of a continuous flow analysis method such as the one described are that as many recordings as required can be made during the study and that the results are available immediately. The need for multiple analysis of samples is avoided, with a consequent saving in technician time. We feel that the application of different principles for the detection of oxygen and of carbon dioxide in the Spirolyt is an advantage of this particular machine.

The correlation between values measured on the Spirolyt and those obtained by routine laboratory methods was excellent and illustrates that the Spirolyt can be used for monitoring of oxygen consumption up to levels of at least $1 \frac{1}{2}$ litres a minute.

\section{SUMMARY AND CONCLUSIONS}

Measurements of oxygen uptake and carbon dioxide production made on the Spirolyt paramagnetic analyser and by micro-Schölander measurement of expired air have been compared at rest and on exercise. Fifty-seven duplicate observations were made on 12 normal subjects at rest and at several work loads. The results indicate satisfactory agreement and show that despite some difficulties in application the Spirolyt can be used for continuous monitoring of oxygen uptake and carbon dioxide production at work loads of up to $1200 \mathrm{kpm}$./minute.

* The manufacturers of this apparatus have informed us that since receiving our comments they have improved the equipment and in particular they have replaced the pump with a quiet version. 